\title{
Iatrogenic medication errors in a paediatric intensive care unit in Durban, South Africa
}

\author{
A Gokhul, ${ }^{1}$ MB ChB, DCH, FCPaed; P M Jeena, ${ }^{1}$ MB ChB, FCPaed, FCP Pulmonol; A Gray, ${ }^{2}$ BPharm, MSc (Pharm), FPS, FFIP \\ ${ }^{1}$ Department of Paediatrics and Child Health, School of Clinical Medicine, College of Health Sciences, Nelson R Mandela School of Medicine, \\ University of KwaZulu-Natal, Durban, South Africa \\ ${ }^{2}$ Division of Pharmacology, Discipline of Pharmaceutical Sciences, School of Health Sciences, Nelson R Mandela School of Medicine, \\ University of KwaZulu-Natal, Durban, South Africa
}

Corresponding author: A Gokhul (ashmikagokhul@yahoo.com)

\begin{abstract}
Background. Iatrogenic medication errors due to calculation errors are an under-reported concern in children.
Objective. To determine the incidence and source of iatrogenic medication errors in a paediatric intensive care unit (PICU).

Methods. A prospective study was conducted in the PICU at Inkosi Albert Luthuli Hospital, Durban, South Africa, over a 3-month period in 2014. Medication-related calculation skills of medical practitioners and nurses were assessed through the voluntary anonymous completion of a questionnaire. Medication errors were recorded either spontaneously or by review of all electronic records of admissions. Errors were classified as delays in the decision to prescribe, prescribing mistakes, dispensing errors and administration issues.

Results. Of 25 staff members sampled, only $6(24.0 \%)$ were able to complete all medication calculations accurately, while $44.0 \%$ ( $n=11$ ) were unable to answer three or more questions correctly. Errors most frequently encountered included failure to calculate rates of infusion and the conversion of $\mathrm{mL}$ to $\mathrm{mEq}$ or $\mathrm{mL}$ to $\mathrm{mg}$ for potassium, phenobarbitone and digoxin. Of the $117 \mathrm{children}$ admitted, 111 ( $94.9 \%$ ) were exposed to at least one medication error. Two or more medication errors occurred in $34.1 \%$ of cases. Of the errors, $73.8 \%$ were detected on chart review and $26.2 \%$ by spontaneous reporting. Overall, $89.2 \%$ of errors occurred during prescribing, with $10.0 \%$ having a $\geq 10$-fold increase or decrease in dosage calculations. Only 2.7\% of medication errors were reported as resulting in adverse events.

Conclusion. Therapeutic skills of healthcare professionals working in the PICU need to be improved to decrease iatrogenic medication errors.
\end{abstract}

S Afr Med J 2016;106(12):1222-1229. DOI:10.7196/SAMJ.2016.v106i12.10940

Pharmacovigilance has been described as 'the science and activities relating to the detection, assessment, understanding and prevention of adverse effects or any other drug-related problems. ${ }^{\text {[1] }}$ It is a responsibility shared between consumers, medical and associated practitioners, regulators, manufacturers and researchers. The World Health Organization (WHO) recognised the importance of pharmacovigilance and created a global centre for reporting of adverse effects of drugs in Uppsala, Sweden. This unit has guided the development of various types of adverse event reporting, including spontaneous reporting, targeted spontaneous reporting, focused active surveillance, cohort reports, pregnancy exposure registry surveillance systems, adverse effects following immunisation surveillance programmes, and a decentralised approach. The National Adverse Drug Event Monitoring Centre at the University of Cape Town is currently being utilised as the reference centre for spontaneous reporting of adverse drug effects in South Africa (SA). In addition, the National Department of Health (NDoH) in SA has adopted a district-based decentralised adverse drug reporting system for antiretroviral therapy, but this programme is not yet operative in all 52 districts. A multidisciplinary task team set up at district level reviews and reports only those errors deemed of national significance to the NDoH.

Medication errors are an important cause of iatrogenic morbidity, mortality and additional health costs in hospitalised patients. In the USA, the estimated cost for medication-related morbidity and mortality in 2000 was USD177.4 billion. ${ }^{[2]}$ While iatrogenic medication errors in children at healthcare facilities in industrialised countries have been well described, there are limited data from developing countries, including SA. ${ }^{[3-6]}$ The incidence of medication errors varies widely between clinical settings and patient populations. Factors that account for this variation include the definition of medication errors, whether medication error was calculated per patient day, medication day or dose administered, and whether the errors were identified by spontaneous reporting or by focused active surveillance. ${ }^{[7]}$ In a 5-week retrospective chart review of paediatric inpatients, Al-Jeraisy et al. ${ }^{[8]}$ documented an overall rate of 56 medicinal errors per 100 medication orders, with one-third occurring in the paediatric intensive care unit (PICU). The most prevalent errors were in dosing $(22.0 \%)$, in the route of administration (12.0\%) and in frequency of dosing (5.4\%). In one of the few safety reports from a PICU in SA, Vermeulen $e t$ al. ${ }^{[9]}$ identified higher rates of adverse effects reporting with a trigger tool method rather than a real-time reporting tool in both retrospective and prospective analysis of data from Red Cross War Memorial Children's Hospital, Cape Town, SA.

A medication error can occur at any one or more of the five stages of medication use, viz. prescription, transcription, dispensing, preparation and administration. Children admitted to a PICU pose unique challenges with regard to the use of medications as they have severe illnesses requiring a large number of medications. Compared with children admitted to a general ward, they are prescribed twice the number of medications. ${ }^{[10]}$ Furthermore, medication dosages in the PICU are often calculated on the basis of an estimated weight or body surface area. Dosing is almost always parenteral, 
and medications require dilution before being administered as an infusion at a specific rate. Medication errors are likely to occur as a result of the large number of prescribed items, the multiple care providers involved, and the extensive detail required in an ICU setting. Patients in these units are often sedated and rely on dedicated professionals and sophisticated technologies and equipment delivering essential care. These patients have little physiological reserve, which potentially increases the risk of adverse events. ${ }^{[10]}$ Lack of adequate training of healthcare professionals, poor understanding of the pharmacokinetics and pharmacodynamics of medications, poor vigilance and lack of medicine-related audits contribute to high rates of medication errors in children. There is a seven-fold increased risk of medication errors in the intensive care unit (ICU) compared with the general ward. ${ }^{[11]}$

In attempting to identify the source of these errors, Rowe et al. ${ }^{[12]}$ studied the calculation skills of paediatric residents in 1993 (34 participants) and 1995 (30 participants), each time by administering anonymously written tests that mirrored real-life paediatric bedside dosing challenges. In both years, $44 \%$ of trainees made at least one medication error, with $11 \%$ (7 of 64) making a 10-fold or greater error in dosage. These seven residents made significantly more errors than the rest of the group. Six of the seven residents were in their first year of training.

\section{Objective}

Currently there is no published literature on iatrogenic medication errors in SA. We conducted the first prospective study to define iatrogenic medication errors in a PICU.

\section{Methods}

This study was conducted prospectively over the 3-month period September - November 2014 in a 14-bed PICU at Inkosi Albert Luthuli Hospital (IALCH), Durban, SA. The unit admits an average of 500 critically ill children aged 0 - 12 years annually and serves a population of 3 million children in the province of KwaZulu-Natal, SA. The PICU functions as a closed unit, staffed by three fulltime subspecialists, one fellow training in critical care and seven registrars, and has a nurse/patient ratio of 1:1. Most of the nurses in the unit $(>80 \%)$ do not have specialised critical care training, and there is constant turnaround of staff due to resignation. The registrars are in training for paediatrics and work in the unit on a 3-monthly rotational basis. The hospital has a computerised physician order entry (CPOE) system for prescribing medication. A pharmacist dispenses electronically submitted medication orders but does not attend to patients at the bedside. On average 1 - 2 patients are admitted to the unit each day, but occasionally 4 - 5 patients may be admitted on a single day. Admissions arrive at all times of the day or night but are usually concentrated in the early evening. There are four registrars on duty between $08 \mathrm{~h} 00$ and $18 \mathrm{~h} 00$, one of whom continues to undertake a 24 -hour shift. A different registrar works between $20 \mathrm{~h} 00$ and $08 \mathrm{~h} 00$ every night. Two consultant ward rounds, one at $10 \mathrm{~h} 00$ and a second at $17 \mathrm{~h} 00$, are done each day.

Medication calculation skills of healthcare staff in the PICU were assessed by requesting medical and nursing staff to voluntarily complete a paper-based questionnaire, adapted from that used by Rowe et al. (Appendix 1). ${ }^{[12]}$ The questionnaire was answered anonymously. There were no time restrictions placed on respondents for completion of the questionnaire. The questionnaire was administered at the onset of the study, during September 2014. Basic calculation skills tested were conversion of millilitres to milliequivalents and milligrams to millilitres and vice versa, pounds to kilograms, and methods of preparing infusions.

The CPOE system at IALCH allows only medical staff to order medication. The medication is usually ordered in milligrams with options for the selection of the frequency and route of administration provided. The program does not auto-calculate the conversion of milligrams to millilitres and there are no safety checks to limit prescriptions below and above therapeutic ranges, or maximum daily doses of medications. Nurses are tasked with the conversion of milligrams to millilitres and administration of medications, and are required to confirm the conversion with a colleague. There is no routine process to check whether this process is undertaken or accurate. At the end of a 7-day period, orders of medications on the system that are not renewed 'fall off' the daily prompts.

For the prospective study, parents and caregivers of all patients admitted to the unit over the study period were informed of the study, and written informed consent in English or isiZulu was obtained. For the spontaneous reporting of medical errors, all staff were reassured that persons responsible for errors or those reporting the incident would not be subject to any legal inquiry. All reports were treated as confidential. For easy access of study material, blank copies of the spontaneous reporting questionnaire were made available in a storage box that was labelled and left in the unit. The questionnaire included demographic data, date, time, number of staff on duty, description of the reason for the patient's admission, list of all medications the patient had received, type and description of medication error, impact and outcome of error, who reported it and whether the error was disclosed to the family. These forms were collected daily and entered into the database.

Focused surveillance of errors by review of the electronic chart of every admission to the PICU over the study period was conducted by the primary investigator at the end of the 3-month study period to identify any medication errors that were missed. All medicine doses were compared with those suggested in a standard reference text. ${ }^{[13]}$ A medication error was defined as any error in the medication process, whether there was an adverse consequence or not. The type and description of medication error included errors relating to the decision to order medication (such as delays in ordering, indications or contraindications), prescribing errors (delays in prescribing, incorrect patient, incorrect medicine, incorrect intravenous rate, incorrect intravenous concentration, incorrect strength, incorrect frequency, incorrect route, duplicate order), dispensing delay (lack of ordering or issuing the medicine), preparation errors (unsterile technique, incorrect intravenous concentration, incorrect medicine used, labelling error), and administration errors (wrong patient, wrong medicine given, incorrect dose given, incorrect intravenous rate, incorrect route, extra dose given, dose omitted, medication given but not prescribed).

The outcomes of medicinal error were classified as fatal (patient died), life-threatening (e.g. respiratory failure requiring intubation, coma, anaphylactic shock), serious (e.g. bleeding, altered mental state, increased plasma creatinine, drop in blood pressure, allergic reaction) or significant (e.g. rash, diarrhoea, thrombocytopenia, nausea/vomiting).

All data were analysed with the assistance of a statistician, using the Statistical Package for Social Sciences (SPSS) version 21 (IBM, USA). Results were provided as descriptive statistics such as frequencies, percentages, and means and standard deviations. The study received ethical approval from the Biomedical Research Ethics Committee of the University of KwaZulu-Natal (ref. no. BE250/13). 


\section{Results}

There were 117 patients admitted to the PICU during the 3-month period. The most common primary diagnosis was acute respiratory failure secondary to bronchopneumonia (64.0\%), with acute respiratory distress syndrome seen in $23.3 \%$ of these cases. Of the patients admitted, 19.0\% of admissions were HIV-infected, confirmed on two HIV DNA polmerase chain reaction-positive results; $93.2 \%$ of admissions were accepted as acute emergencies and $6.8 \%$ as elective cases.

\section{Errors in calculation}

Twenty-five healthcare professionals out of a total of 74 (63 nursing and 11 medical practitioners) completed the 11 questions in the medication calculation questionnaires. The level of expertise was known via the questionnaire for $48.0 \%(12 / 25)$ of the respondents, the majority of these $(75.0 \%, 9 / 12)$ being nurses. Only six staff members answered all 11 questions correctly. Eleven staff members (44.0\%) incorrectly answered three or more questions, and this was proportionally equally spread between medical and nursing staff. Common errors included failure to calculate rates of infusion, the conversion of millilitres to milliequivalents for potassium, phenobarbitone and digoxin, and 10- to 1000 -fold higher or lower doses for the individual medications (Tables 1 and 2).

\section{Spontaneous and active focused reporting of medication errors}

Of the 117 admissions, 111 (94.9\%) experienced at least one iatrogenic medication error. Medication errors were spontaneously reported in 29 cases $(26.1 \%)$, while an additional 82 errors $(73.9 \%)$ were detected by means of electronic chart review. Spontaneous reports were completed mostly by medical staff (73.9\%), but also by nursing staff (27.1\%). The majority of errors occurred in male patients (63.1\%) and those $<6$ months of age (69.4\%). Thirty-two percent of subjects with medication errors were severely underweight for age (WHO $z$-score $<3)$. Common medications where errors were noted included antibiotics (91.9\%), analgesics (78.4\%) and sedatives (73.9\%) (Fig. 1). The greatest number of errors (45.1\%) occurred between $08 \mathrm{~h} 00$ and $16 \mathrm{~h} 00$ on weekdays, a period when there is an active turnaround of patients (Fig. 2). There was no increase in errors over weekends or public holidays, when there are fewer staff members on duty.
Of the 111 patients in whom a medication error was reported or detected, $65.8 \%$ had 1 medication error, $18.0 \%$ had 2 medication errors, $8.1 \%$ had 3 medication errors, $6.32 \%$ had 4 errors, and $1.8 \%$ had 5 errors. Delays in the decision to prescribe were noted in only $4.5 \%$ of patients. Actual prescribing errors occurred in $89.2 \%$ of patients, with delay in ordering (22.5\%), incorrect concentration (19.8\%), duplicate ordering (16.2\%) and lack of renewal of scripts (38.7\%) being the most common mistakes. Preparation errors comprised $6.3 \%$ of total errors. Administration errors mainly consisted of dose omissions (16.2\%) and administering medicines that were not

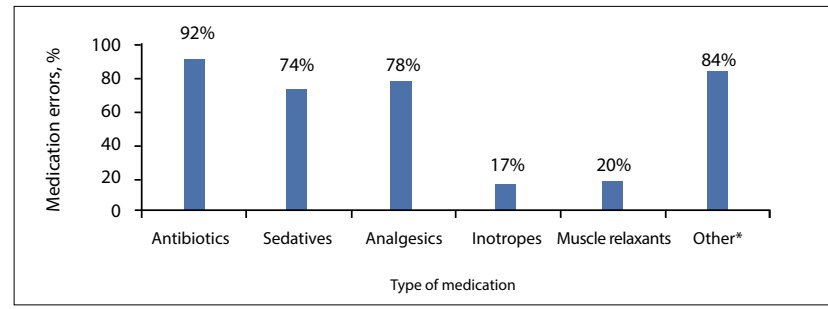

Fig. 1. Errors according to type of medication. $\left({ }^{*}\right.$ Antiretrovirals, antituberculosis drugs, supplements.)

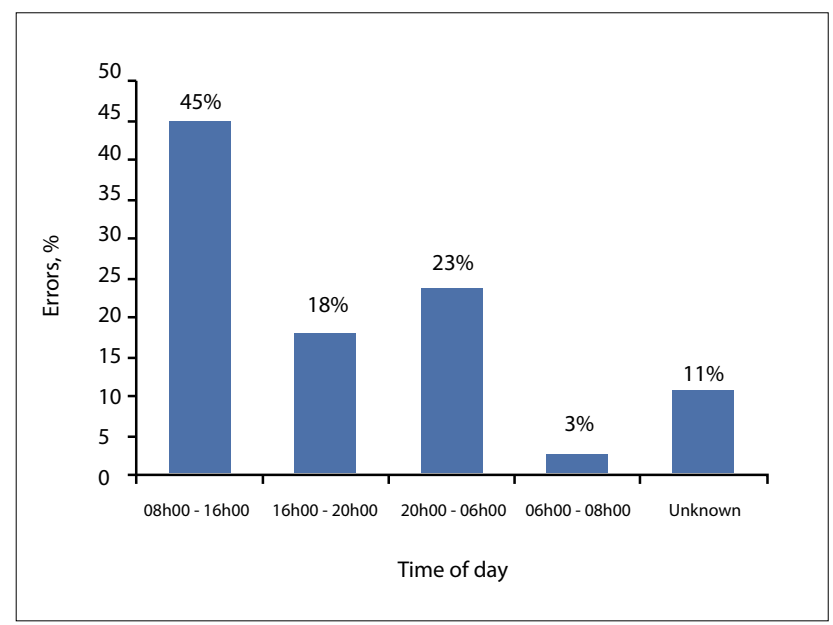

Fig. 2. Timing of medication errors.

Table 1. Calculation skills and common errors among healthcare professionals $(N=25)$ completing the theoretical questionnaire (11 questions)

\begin{tabular}{|c|c|c|c|c|}
\hline Questions & $\begin{array}{l}\text { Correct, } \\
n(\%)\end{array}$ & $\begin{array}{l}\text { Incorrect, } \\
n(\%)\end{array}$ & $\begin{array}{l}\text { Did not answer, } \\
n(\%)\end{array}$ & $\begin{array}{l}\text { Did not know, } \\
n(\%)^{\star}\end{array}$ \\
\hline Potassium chloride $\mathrm{mEq}$ to $\mathrm{mL}$ & $17(68.0)$ & $6(24.0)$ & $2(8.0)$ & $8(24.0)$ \\
\hline Digoxin $\mathrm{mL}$ to $\mathrm{mg}$ & $19(76.0)$ & $5(20.0)$ & $1(4.0)$ & $6(24.0)$ \\
\hline Phenobarbitone $\mathrm{mL}$ to $\mathrm{mg}$ & $18(72.0)$ & $7(28.0)$ & - & $7(28.0)$ \\
\hline Pounds to $\mathrm{kg}$ & $13(52.0)$ & $3(12.0)$ & $9(36.0)$ & $12(48.0)$ \\
\hline Dopamine infusion & $11(44.0)$ & $3(12.0)$ & $11(44.0)$ & $14(56.0)$ \\
\hline
\end{tabular}

Table 2. The magnitude of the errors $(N=25)$

\begin{tabular}{|c|c|c|c|c|c|c|c|c|}
\hline \multirow[b]{2}{*}{$\begin{array}{l}\text { Questions on drug calculation } \\
\text { skills }\end{array}$} & \multirow[b]{2}{*}{$\begin{array}{l}\text { Incorrect } \\
\text { answer, } n(\%)\end{array}$} & \multicolumn{7}{|c|}{ Significant incorrect doses, $n$} \\
\hline & & $\begin{array}{l}<15 \times \\
\text { more }\end{array}$ & $\begin{array}{l}15 \times \\
\text { more }\end{array}$ & $\begin{array}{l}20 \times \\
\text { more }\end{array}$ & $\begin{array}{l}1000 \times \\
\text { more }\end{array}$ & $\begin{array}{l}10 \times \\
\text { less }\end{array}$ & $\begin{array}{l}100 \times \\
\text { less }\end{array}$ & $\begin{array}{l}1000 \times \\
\text { less }\end{array}$ \\
\hline Potassium chloride, $\mathrm{mEq}$ to $\mathrm{mL}$ & $6(24.0)$ & 2 & - & 4 & - & - & - & - \\
\hline Digoxin, $\mathrm{mg}$ to $\mathrm{mL}$ & $2(8.0)$ & - & - & - & - & 1 & 1 & - \\
\hline Digoxin, $\mathrm{mL}$ to $\mathrm{mg}$ & $5(20.0)$ & 1 & 3 & - & 1 & - & - & - \\
\hline Phenobarbitone, $\mathrm{mL}$ to $\mathrm{mg}$ & $7(28.0)$ & 2 & - & - & - & 3 & 1 & 1 \\
\hline
\end{tabular}


prescribed (15.3\%). Only $2.7 \%$ of medication errors were reported as resulting in adverse events (Table 3 ).

Of the 111 patients with medication errors, 12 (10.8\%) had significant dosage errors (3.2- and 32-fold increases in the dose of phenobarbitone, 1.5- and 20 -fold increases in the dose of acyclovir, 10 -fold increase in the dose of tazobactam, 3.5 -fold increase in the dose of fluconazole, 1.3 -fold increase in the dose of sildenafil, 4 -fold decrease in the dose of meropenem, 20 -fold decrease in the dose of captopril, and a 2.85 -fold decrease and 10-fold increase in the dose of furosemide infusion). Of these 12 patients 4 died, none apparently from the direct effect of the medication error. In the remaining 8 patients, toxic phenobarbitone levels, renal impairment caused by furosemide and increased septic markers as a result of an inadequate dose of meropenem were reported (Table 2).

\section{Discussion}

The major finding in this study of iatrogenic medication errors in an SA PICU was the poor medication-related calculations skills demonstrated by healthcare professionals. The dosing errors in calculations ranged from 10 to 1000 times more or less than the precise dose. As these questionnaires were answered in the individuals' own time, factors such as excessive workload or fatigue were unlikely to have contributed to the poor results. ${ }^{[14,15]}$ Rowe et al. ${ }^{[8]}$ had similar findings, showing that a substantial proportion of paediatric trainees made life-threatening mistakes while calculating medication doses under optimal test conditions. These findings suggest that testing of calculation skills should be mandatory before any nurse or medical

Table 3. Types of common medication errors $(N=111)$

\begin{tabular}{ll}
\hline Medication errors & $\boldsymbol{n}(\%)$ \\
\hline Decision to prescribe & \\
$\quad$ Drug indicated but delay in starting it & $2(1.8)$ \\
Contraindication & $3(2.7)$ \\
Prescribing/ordering errors & \\
$\quad$ Delay in order & $25(22.5)$ \\
Wrong patient & $1(0.9)$ \\
Wrong drug & $2(1.8)$ \\
Incorrect rate & $2(1.8)$ \\
Incorrect strength & $22(19.8)$ \\
Incorrect frequency & $4(3.6)$ \\
Incorrect route & $5(4.5)$ \\
Duplicate order & $18(16.2)$ \\
Failure to renew order & $43(38.7)$ \\
Preparation errors & \\
Unsterile technique & $1(0.9)$ \\
Incorrect drug & $2(1.8)$ \\
Incorrect intravenous concentration & $1(0.9)$ \\
Labelling error & $3(2.7)$ \\
Administration errors & \\
Dose omitted & $18(16.2)$ \\
Extra dose given & $2(1.8)$ \\
Given but not ordered & $17(15.3)$ \\
Error resulting in adverse event & $3(2.7)$ \\
(e.g. furosemide causing renal impairment) & \\
Who reported error? & \\
Nurse & $30(27.0)$ \\
Doctor & $81(73.0)$ \\
Was error disclosed to family? & $111(100)$ \\
No & \\
&
\end{tabular}

professional is allowed to work in a PICU. Remedial steps should be in place to prevent a poor standard of care being delivered. A recent report in the UK General Medical Council's Tomorrow's Doctor Manual has supported the move of improved teaching of prescription to undergraduate and postgraduate medical practitioners. ${ }^{[16,17]}$

Our findings also support the need for medical undergraduates to be exposed to a curriculum that teaches the core elements of clinical pharmacology and therapeutics. ${ }^{[18]}$ Heaton et al. ${ }^{[19]}$ published a 2-year web-based survey that looked at undergraduate preparation for prescribing. Seventy-four percent of 2413 participants felt that the amount of clinical pharmacology and therapeutics teaching they received was 'too little', and $56 \%$ felt that their assessment of this subject matter was inadequate. ${ }^{[19]}$ In SA, the need for an urgent review of teaching and assessment of competence in relation to prescribing at medical and nursing schools is clear. Healthcare graduates should ideally be examined in a 'must-pass' clinical pharmacology and therapeutics examination in their final year of training.

Spontaneous reporting is a pharmacovigilance tool with limited value, mainly used as a means of signal detection. ${ }^{[20,21]}$ In the spontaneous reporting and focused active surveillance review of the electronic charts, very high rates of medication errors were identified. The majority of these errors occurred during a time when there was a high burden of admissions with adequate staff numbers on duty. Possible reasons for these errors could be poor knowledge levels of staff members and an excessive workload. Furthermore, the hospital uses a computerised system for prescribing, which, despite the training provided, may have proved challenging for staff with limited computer knowledge ${ }^{[18]}$ In addition, the software utilised does not include decision support elements, such as alerts for incorrect dosages, drug-drug interactions, contraindications or associated allergies, or advice about dosing in the presence of renal or hepatic failure. If medication is maintained as ICU ward stock, a second staff member should be mandated to check the prescription as a routine before it is administered. The presence of full-time pharmacists on wards or in decentralised pharmacies could also assist in intercepting errors before they occur. Hand-held devices such as smartphones with medication dosage applications could also be used at the bedside to assist in calculating dosages. As prescribing errors accounted for $89.2 \%$ of all medication errors, these measures could have a significant impact on the quality of care provided.

Our finding of a very high prevalence of medication errors differed from those reported in other studies. Kaushal et al. ${ }^{[22]}$ used prospective chart review to study medication errors in 2001, in which they reviewed 10778 medication orders and found 616 medication errors (5.7\%), 115 potential adverse drug events (1.1\%) and 26 adverse drug events $(0.24 \%)$. Most of the potential adverse drug events occurred at the stage of medication ordering (79\%) and involved incorrect dosing (34\%), especially of anti-infective medicines (28\%) and intravenous medication (54\%). In 2000, Ross et al. ${ }^{[3]}$ reviewed 5 years of medication errors among admissions and reported an incidence of $0.15 \%$. During the same period, 195 spontaneous reports were recorded, mainly by nurses (59\%), with dosing errors (commonly with antibiotics) at the time of ordering (28\%) and errors with the intravenous administration (56\%) frequently identified. A $>10$-fold error occurred in $8 \%$ of these patients. The high rates of iatrogenic medication errors detected are likely to be due to the use of spontaneous reporting and chart review, rather than reliance on the former method alone.

The lack of specific monitoring of children with medication errors is of concern. In 2008, Passi and Parihar ${ }^{[5]}$ performed a prospective chart review of children with medication errors over a 6-month 


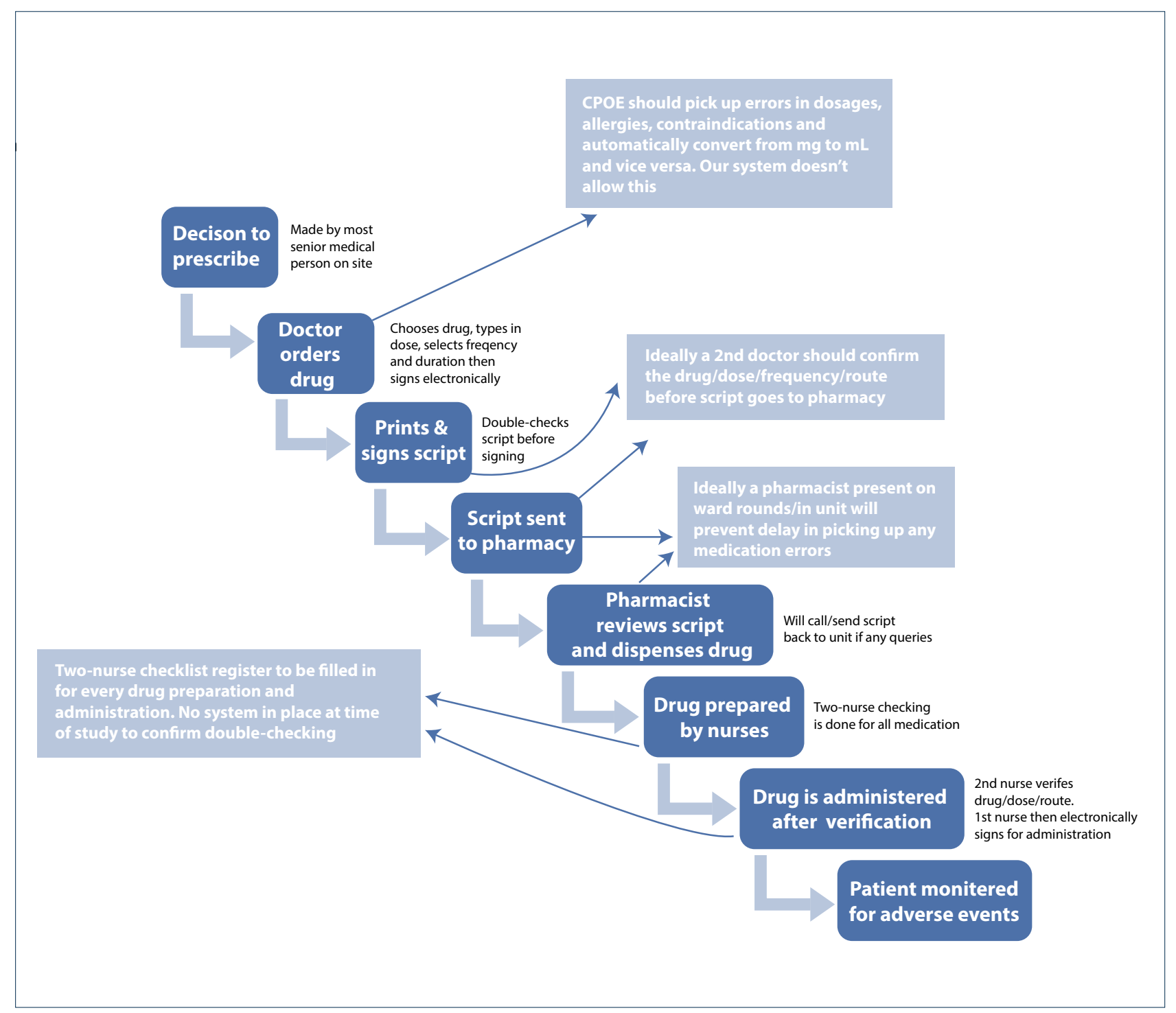

Fig. 3. Medication process recommended by the PICU at IALCH.

period. Almost two-thirds of the errors occurred in an ICU, with adverse effects rarely reported. These findings are similar to those in our study. Of note, in our study no parents were informed about any of the medication errors that occurred. While this is understandable given prevalent concerns around ligation, it is not acceptable. Senior clinicians should act by undertaking frequent checks for early detection and management of these errors. They should also spend time counselling parents about any errors that have been reported.

\section{Study limitations}

Our study had several limitations, including being from a single study site. The incidence of errors was estimated based on the number of admissions to the PICU over the study period and not on the number of medication orders that were issued. Administration and preparation errors may also have been missed, as there was no system in place to adequately monitor each medicine prepared or administered. The accuracy of the data generated was not checked by an independent reviewer.

\section{Conclusion}

The high incidence of medication errors reported and detected in the PICU probably results from poor medication-related calculation skills and knowledge on the part of both medical and nursing professionals. All medical and nursing colleges should consider whether their undergraduate curricula adequately address the development of necessary numeracy and clinical therapeutic skills among their graduates. ${ }^{[23]}$ All medical and nursing staff should have their calculation skills tested before commencing work in the PICU. Appropriate remedial steps should follow in order to reduce iatrogenic morbidity, mortality and the financial burden to the healthcare system. The complexity of the prescribing process supports the position that multiple rather than single interventions would help reduce the burden of medication errors (Fig. 3). Given the increasing burden of litigation in SA, research into these areas of healthcare is essential.

Acknowledgements. We thank the parents of the children enrolled into the study for granting permission for their child's data to be included. Our sincere appreciation goes to the chief executive officer of IALCH, Dr S Mtshali, and the medical manager, Dr M E L Joshua, for permission to conduct this study.

1. World Health Organization. The Importance of Pharmacovigilance - Safety and Monitoring of Medication. Geneva: WHO, 2012:4-8. http://apps.who.int/medicinedocs/en/d/Js4893e/10.htm (accessed 7 November 2016).

2. Ernst FR, Grizzle AJ. Drug related morbidity and mortality: Updating the cost of illness model. J Am Pharm Assoc (Wash) 2001;41(2):192-199. 
3. Ross LM, Wallace J, Paton YJ. Medication errors in a paediatric teaching hospital in the UK: Five years operational experience. Arch Dis Child 2000;83(6):492-497. http://dx.doi.org/10.1136/adc.83.6.492 4. Carvalho PRA, Carvalho GC, Alievi PT, Martinbiancho J, Trotta EA. Prescription of drugs not appropriate for children in a pediatric intensive care unit. J Pediatr (Rio J) 2003;79(5):397-402. http:// appropriate for children in a p
dx.doi.org/10.2223/IPED. 1069

5. Passi GR, Parihar M. Medical errors in paediatric practice. Indian Pediatr 2008;45(7):586-589.

6. Sullivan JE, Buchino JJ. Medication errors in paediatrics - the octopus evading defeat. J Surg Oncol 2004;88(3):182-188. http://dx.doi.org/10.1002/JSO.20126

. Camire E, Moyen E, Stelfox HT. Clinical review: Medication errors in critical care. Can Med Assoc J 2009;180(9):936-943. http://dx.doi.org/10.1503/cmaj.080869

8. Al-Jeraisy MI, Alanazi MQ, Abolfotouh MA. Medication prescribing errors in a paediatric inpatient tertiary care setting in Saudi Arabia. BMC Res Notes 2011;4:294. http://dx.doi.org/10.1186/1756-0500-4-294

9. Vermeulen JM, van Dijk M, van der Starre C, et al. Patient safety in South Africa, PICU adverse event registration. Pediatr Crit Care Med 2014;15(5):464-470. http://dx.doi.org/10.1097/ PCC. 0000000000000114

10. Wimler A, Louie K, Dodek P, Wong H, Ayas N. Incidence of medication errors and adverse drug events in the ICU: A systemic review. Qual Saf Health Care 2010;19(5):e7. http://dx.doi.org/10.1136/ qshc. 2008.030783

11. Wilson DG, McArtney RG, Newcomber RG, et al. Medication errors in paediatric practice: Insights from a continuous quality improvement approach. Eur J Pediatr 1998;157(9):769-774.

12. Rowe C, Koren T, Koren G. Errors by paediatric residents in calculating drug doses. Arch Dis Child Rowe C, Koren T, Ko
1998; $79(1): 56-58$.

13. Shann F. Drug Doses. 15th ed. Melbourne, Australia: Intensive Care Unit, Royal Children's Hospital, 2010

14. Fahrenkopf AM, Sectish TC, Barger LK, et al. Rates of medication errors among depressed and burnt out residents: Prospective cohort study. BMJ 2008;336:488. http://dx.doi.org/10.1136/ bmj.39469.763218.BE
15. Doherty C, McDonell C. Tenfold medication errors: 5 years' experience at a University-affiliated pediatric hospital. Pediatrics 2012;129(5):916-924. http://dx.doi.org/10.1542/peds.2011-2526

6. Porter E, Barcega B, Kim TY. Analysis of medication errors in simulated pediatric resuscitation by residents. West J Emerg Med 2014;15(4):486-490. http://dx.doi.org/10.5811/westjem.2014.2.17922

17. Maxwell S, Walley T. Teaching safe and effective prescribing in UK medical schools: A core curriculum 7. Maxwell S, Walley T. Teaching safe and effective prescribing in UK medical schools: A core curriculum
for tomorrow's doctors. Br J Clin Pharmacol 2003;55(6):496-503. http://dx.doi.org/10.1046/j.1365for tomorrow's doct
$2125.2003 .01878 . x$

18. General Medical Council. Good practice in prescribing and managing medicine and devices. 2013. http://www.gmc-uk.org/guidance (accessed 6 November 2016).

19. Heaton A, Webb DJ, Maxwell SRJ. Undergraduate preparation for prescribing: The view of 2413 UK medical students and recent medical graduate. Br J Clin Pharmacol 2008;66(1):128-134. http://dx.doi. org $/ 10.1111 / j .1365-2125.2008 .03197 . x$

20. Pal SN, Duncombe C, Falzon D, Olsson S. WHO strategy for collecting safety data in PUBLIC health programmes: Completing spontaneous reporting systems. Drug Saf 2013;36(2):75-81. http://dx.doi. org/10.1007/s40264-012-0014-6

21. Carpecken CW, Sharek PJ, Longhurst C, Pageler NM. A clinical case of electronic health record drug alert fatigue: Consequences for patient outcome. Pediatrics 2013;131(6):e1970-e1073. http://dx.doi. $\mathrm{org} / 10.1542 /$ peds.2012-3252

22. Kaushal R, Bates D, Landigran C, et al. Medication errors and adverse drug events in paediatric inpatients. JAMA 2001;285(16):2114-2120. http://dx.doi.org/10.1001/jama.285.16.21141

23. Walsh KE, Kaushal R. How to avoid paediatric medication errors: A user's guide to the literature. Arch Dis Child 2005;90(7):698-702. http://dx.doi.org/10.1136/adc.2003.048827

Accepted 26 April 2016 


\section{Appendix 1. Questionnaire used to test drug dose calculation skills}

This is an anonymous questionnaire.

Please make the following dose calculations. Use a calculator or any other means you use routinely. If you have any comments about any of the doses, please write in the 'comment' space.

DESIGNATION (e.g. registrar/nurse/fellow/consultant):

YEAR OF STUDY:

DATE:

\section{TIME TOOK FOR YOU TO COMPLETE QUESTIONNAIRE:}

1. A 3-day-old baby is treated with $25 \mathrm{mg}$ of phenytoin intravenously. The ampoule contains 50 $\mathrm{mg} / \mathrm{mL}$. The baby should receive $\mathrm{mL}$.

Comment:

2. $108 \mathrm{mEq}$ of potassium chloride has to be added to intravenous fluids. The ampoule contains $20 \mathrm{~mL}$ with a potassium concentration of $3.2 \mathrm{mEq} / \mathrm{mL}$. You should inject $\mathrm{mL}$ of the solution.

\section{Comment:}

3. A child with hyperglycaemia has to receive $18 \mathrm{U}$ of insulin. The solution contains $40 \mathrm{U} / \mathrm{mL}$. The child should receive $\mathrm{mL}$.

Comment:

4. A preterm infant is to receive $0.6 \mathrm{~g}$ of calcium gluconate intravenously. The solution contains $10 \%$ calcium gluconate in $(10 \mathrm{~g} / 100 \mathrm{~mL})$ of the solution. The infant should receive $\mathrm{mL}$.

\section{Comment:}

5. A toddler is treated with $62 \mathrm{mg}$ of gentamicin intravenously. The solution contains $40 \mathrm{mg} / \mathrm{mL}$ of gentamicin. The child should receive $\mathrm{mL}$.

Comment:

6. A baby is treated with theophylline intravenously. The order was $25 \mathrm{mg}$. The ampoule contains $250 \mathrm{mg} / 5 \mathrm{~mL}(50 \mathrm{mg} / \mathrm{mL})$. The baby should receive $\mathrm{mL}$.

Comment: 
7. A 12-month-old child is to receive $0.625 \mathrm{mg}$ of intravenous digoxin during digitalisation. Each millilitre of digoxin contains $0.250 \mathrm{mg}$. How many millilitres of digoxin should be received? $\mathrm{mL}$

Comment:

8. A $2 \mathrm{~kg}$ child received $2.6 \mathrm{~mL}$ of digoxin $(0.250 \mathrm{mg} / \mathrm{mL})$. How many milligrams did the child receive? mg

\section{Comment:}

9. A 2-month-old infant was prescribed $0.3 \mathrm{~mL}$ of phenobarbitone for seizures. The concentration of the solution is $30 \mathrm{mg} / \mathrm{mL}$. She received $3 \mathrm{~mL}$ instead. How many milligrams were given? mg

\section{Comment:}

10. A child weighs $94 \mathrm{lbs}$. How many $\mathrm{kg}$ does he weigh? $\mathrm{kg}$

\section{Comment:}

11. A $3.5 \mathrm{~kg}$ infant needs to be started on $10 \mu \mathrm{g} / \mathrm{kg} / \mathrm{min}$ of dopamine. How would you mix the infusion, and what rate would you run the infusion?

Comment: 